\title{
Helicobacter pylori filtrate impairs spatial learning and memory in rats and increases $\beta$-amyloid by enhancing expression of presenilin-2
}

\author{
Xiu-Lian Wang ${ }^{1,2+}$, Ji Zeng ${ }^{3+}$, Jin Feng ${ }^{1}$, Yi-Tao Tian ${ }^{1}$, Yu-Jian Liu ${ }^{1}$, Mei Qiu ${ }^{1}$, Xiong Yan ${ }^{1}$, Yang Yang ${ }^{1}$, \\ Yan Xiong ${ }^{1}$, Zhi-Hua Zhang ${ }^{2}$, Qun Wang ${ }^{1}$, Jian-Zhi Wang ${ }^{1 *}$ and Rong Liu ${ }^{1 *}$ \\ ' Key Laboratory of Neurological Disease, Ministry of Education, Department of Pathophysiology, Tongji Medical College, Huazhong University of Science and \\ Technology, Wuhan, China \\ 2 Department of Pathology, Hubei University of Chinese Medicine, Wuhan, China \\ ${ }^{3}$ Department of Clinical Laboratory, Wuhan Pu Ai Hospital, Huazhong University of Science and Technology, Wuhan, China
}

\section{Edited by:}

Brian Joseph Balin, Philadelphia College of Osteopathic Medicine, USA

\section{Reviewed by:}

Ashok Kumar, University of Florida, USA

Brian Joseph Balin, Philadelphia College of Osteopathic Medicine, USA

\section{*Correspondence:}

Jian-Zhi Wang and Rong Liu, Key Laboratory of Neurological Disease, Ministry of Education, Department of Pathophysiology, Tongji Medical College, Huazhong University of Science and Technology, Hangkong Road 13, Wuhan 430030, China e-mail:wangjz@mails.tjmu.edu.cn; rong.liu@hust.edu.cn

these authors have contributed equally to this work.
Helicobacter pylori (H. pylori) infection is related with a high risk of Alzheimer's disease (AD), but the intrinsic link between $H$. pylori infection and AD development is still missing. In the present study, we explored the effect of $H$. pylori infection on cognitive function and $\beta$-amyloid production in rats. We found that intraperitoneal injection of $H$. pylori filtrate induced spatial learning and memory deficit in rats with a simultaneous retarded dendritic spine maturation in hippocampus. Injection of $H$. pylori filtrate significantly increased $A \beta_{42}$ both in the hippocampus and cortex, together with an increased level of presenilin-2 (PS-2), one key component of $\gamma$-secretase involved in A $\beta$ production. Incubation of $H$. pylori filtrate with N2a cells which over-express amyloid precursor protein (APP) also resulted in increased PS-2 expression and $A \beta_{42}$ overproduction. Injection of Escherichia coli (E.coli) filtrate, another common intestinal bacterium, had no effect on cognitive function in rats and $A \beta$ production in rats and cells. These data suggest a specific effect of $H$. pylori on cognition and $A \beta$ production. We conclude that soluble surface fractions of $H$. pylori may promote $A \beta_{42}$ formation by enhancing the activity of $\gamma$-secretase, thus induce cognitive impairment through interrupting the synaptic function.

Keywords: Alzheimer's disease, Helicobacter pylori, learning, memory, $A \beta_{42}$, presenilin-2

\section{INTRODUCTION}

Alzheimer's disease (AD) is the most common type of dementia; patients show hippocampus-dependent spatial memory impairment in the incipient stage of the disease (Lithfous et al., 2013). Pathologically, $\mathrm{AD}$ is characterized by the deposition of extracellular senile plaques (SP) and formation of intracellular neurofibrillary tangles (NFT) within the afflicted brains (Braak and Braak, 1992). The SP are mainly composed of $\beta$-amyloid $(A \beta)$, surrounded by dystrophic neuritis. Numerous studies suggest the $A \beta$ toxicity in promoting the development of $\mathrm{AD}$, such as influencing calcium homeostasis (Mattson et al., 1993; Wu et al., 1997), activating caspases (Harada and Sugimoto, 1999), stimulating protein phosphorylation (Busciglio et al., 1995), and causing mitochondrial abnormalities (Rui et al., 2006; Wang et al., 2008). $A \beta$ is also reported to disrupt hippocampal synaptic plasticity (Walsh et al., 2002; Wang et al., 2002; Li et al., 2009), the latter, is supposed to be the base of hippocampus-dependent learning and memory (Muller et al., 2002). Thus, $A \beta$ plays an important role in inducing cognitive impairment and $\mathrm{AD}$-like pathologic changes. But till now the upstream factors that promoting $A \beta$ overproduction in $\mathrm{AD}$ has not been fully elucidated.

$A \beta$ is produced by the cleavage of amyloid precursor protein (APP) through $\beta$ and $\gamma$-secretase. Abnormal enhanced activity of $\beta$ and $\gamma$-secretase may underlie $A \beta$ overproduction. It is well known that gene mutations of presenilin (PS)-1 and PS-2, key protein members of $\gamma$-secretase, are causative for increased $\mathrm{A} \beta$ production in familial $\mathrm{AD}$ (Borchelt et al., 1996; Duff et al., 1996; Citron et al., 1997; Xia et al., 1997). However, the mechanism leading to abnormal $\gamma$ secretase activation in the majority sporadic $\mathrm{AD}$ patients is still unclear.

Helicobacter pylori (H. pylori) is a gram-negative bacterium which chronically infects more than one half of the world's population. Recently, several clinical surveys and investigations suggest a possible relationship of $H$. pylori infection and AD development. AD patients have a higher prevalence of $H$. pylori than controls (Kountouras et al., 2006); increased levels of $H$. pylori antibodies are detected both in plasma and cerebrospinal fluid of AD patients (Malaguarnera et al., 2004; Kountouras et al., 2009a). AD patients infected by $H$. pylori tend to be more cognitively impaired (Roubaud-Baudron et al., 2012), and H. pylori eradication therapy has a beneficial effect on $\mathrm{AD}$ patients with H. pylori infection (Kountouras et al., 2009b, 2010). However, all these investigations are based on clinical observation, till now the direct laboratory evidence link $H$. pylori infection and $\mathrm{AD}$ is still lacking. 
In the present study, we explored the effect of soluble $H$. pylori surface fractions on the cognitive function and $A \beta$ production in rats. We found that intraperitoneal injection of $H$. pylori filtrate could induce spatial learning and memory impairment in rats, impair the maturation of spines, and increase $A \beta_{42}$ production both in hippocampus and cortex, together with enhanced expression of PS-2. Thus, soluble surface fractions of $H$. pylori may promote $A \beta_{42}$ production by enhancing the activity of $\gamma$-secretase, and induce cognitive impairment through interrupting the synaptic function.

\section{MATERIALS AND METHODS ANTIBODIES AND CHEMICALS}

Rabbit polyclonal antibodies (pAb) against N-methyl-D-aspartic acid receptor (NMDA)-NR2A, NR2B, NR1, postsynaptic density (PSD)-93, PSD-95, Pan-Cadherin (1:1000), and mouse monoclonal antibody (mAb) DM1A against $\alpha$-tubulin (1:2000) were all from Abcam (Cambridge, UK). PAb against $\alpha$-amino3-hydroxy-5-methyl-4-isoxazolepropionic acid (AMPA)-receptor GluR1 (1:500) and mAb against AMPA-GluR2 (1:1000) were from Millipore (Billerica, MA, USA). PAbs against $\beta$-site APP cleaving enzyme (BACE)-1 and PS-2 (1:500) were from Santa Cruz (Santa Cruz, CA). MAb against PS-1 was from Chemicon (Temecula, CA). Secondary antibodies for Western blotting antirabbit or anti-mouse IgG conjugated to IRDyeTM were from Licor Biosciences (Lincoln, NE, USA). Other reagents were of the highest quality available and obtained from commercial sources.

\section{PREPARATION OF H. PYLORI AND E. COLI FILTRATES}

H. pylori strain TN2GF4 (Ohkusa et al., 2003) was a gift from Dr. Zhu Liang-ru (Department of Digestive Internal Medicine, Union Hospital, Huazhong University of Science and Technology), E.coli strain 25922 was from American Type Culture Collection (Manassas, VA, USA). H. pylori bacteria were plated onto Brucella agar supplemented with 5\% horse blood (BBL, Becton Dickinson Microbiology, Cockeysville, MD, USA) and incubated at $37^{\circ} \mathrm{C}$ in a microaerophilic environment for 3-7 days. E.coli bacteria were plated onto blood agar (Columbia agar, bio-merieux, France) and incubated at $37^{\circ} \mathrm{C}$ for $24 \mathrm{~h}$. The bacteria were harvested into pyrogen-free Dulbecco's PBS (Cellgro, Mediatech, Herndon, VA), then pelleted by centrifugation at $4000 \mathrm{~g}$ for $10 \mathrm{~min}$, and bacterial numbers were determined by re-suspension in PBS to an OD600 $\mathrm{nm}$ of 1.5, corresponding to $3.6 \times 10^{8} \mathrm{CFU} / \mathrm{ml}$ as described previously (Keates et al., 1999). Defined numbers of bacteria were then re-suspended in antibiotic free Opti-MEM/DMEM medium (1:1) medium for $30 \mathrm{~min}$ at $37^{\circ} \mathrm{C}$, pelleted at $4000 \mathrm{~g}$ for $10 \mathrm{~min}$, the supernatants were then filtered through a $0.2 \mu \mathrm{m}$ pore size filter (Acrodisc, Gelman, Ann Arbor, MI) and collected. The filtrates were diluted in Opti-MEM/DMEM medium (1:2) (we have previously demonstrated that $H$. pylori filtrate in this concentration could induce Alzheimer-like tau hyperphosphorylation) and stored at $-20^{\circ} \mathrm{C}$ for use.

\section{ANIMAL TREATMENTS AND BEHAVIOR TEST IN MORRIS WATER MAZE}

Three months old $(220 \pm 20 \mathrm{~g})$ male Sprague Dawley rats (Grade: SPF) were supplied by the Experiment Animal Center of Tongji Medical College, Huazhong University of Science and Technology. All animal experiments were performed according to the "Policies on the Use of Animals and Humans in Neuroscience Research" revised and approved by the Society for Neuroscience in 1995. The proposal and experimental design were reviewed and approved by the Institutional Ethics Committee of Tongji Medical College, Huazhong University of Science and Technology. The rats were kept at $22 \pm 2{ }^{\circ} \mathrm{C}$ on daily $12 \mathrm{~h}$ light-dark cycles and received food and water ad libitum. The rats $(n=34)$ were pretrained in Morris water maze (MWM) (Morris, 1984) to search a hidden platform under the water for 7 days. At the end of pre-training, rats which could find the platform within $15 \mathrm{~s}$ were selected and randomly divided into three experimental groups ( $n=9$ for each group) and received intraperitoneal injection of H. pylori, E.coli filtrate or the same volume of DMEM/Opti-MEM medium (1:1) as control $(280 \mu \mathrm{l} / \mathrm{rat} /$ day $)$ for 7 days. On day 4 of injection the spatial memory of the rats in the MWM was measured. Then the rats were trained again in MWM for 3 days, with the platform placed in a new quadrant (re-learning). Spatial memory retention for the second learning was measured $24 \mathrm{~h}$ later (day 8, one day after the last injection). On day 9, motor ability of the rats was tested in the MWM with a visible platform. The rats were then deeply anesthetized and decapitated, and the hippocampal extracts or brain slices were prepared for further studies. The timeline of the behavior test is described in Figure 1A.

\section{NISSL STAINING}

The rats $(n=3)$ were deeply anesthetized with intraperitoneal injection of chloral hydrate $(1 \mathrm{~g} / \mathrm{kg})$ and then fixed by transcardial perfusion with $0.9 \% \mathrm{NaCl}$, followed by $4 \%$ paraformaldehyde in $100 \mathrm{mM}$ phosphate buffer (PB). After perfusion, the brains were postfixed in the same solution overnight at $4^{\circ} \mathrm{C}$. Coronal sections of the brain were cut ( $30 \mu \mathrm{m}$ thick) using Vibratome (Leica, S100, TPI), soaked in $1 \%$ toluidine blue for $3 \mathrm{~min}$. Sections were then dehydrated using $95 \%$ and $100 \%$ ethanol solutions, transparented using xylene, placed under cover slips and analyzed with a microscope (Nikon, 90i, Tokyo, Japan).

\section{GOLGI STAINING}

The rats $(n=3)$ were deeply anesthetized and then fixed by transcardial perfusion with $0.5 \% \mathrm{NaNO}_{2}$ followed by $4 \%$ formaldehyde and potassium dichromate with chloral hydrate which were mixed in $4 \%$ formaldehyde. After perfusion, the brains were postfixed in potassium dichromate with chloral hydrate mixed liquid for 3 days. Then the brains were moved into $1 \% \mathrm{AgNO}_{3}$ solution for 3 days. Coronal sections of the brain were cut $(30 \mu \mathrm{m}$ thick) using Vibratome (Leica, S100, TPI). Sections were dehydrated using a graded series of ethanol solutions, transparented using xylene, placed under cover slips and analyzed with a microscope (Nikon, 90i, Tokyo, Japan).

\section{CELL CULTURE AND TREATMENT}

N2a/APP (N2a stably transfected with human APP) cells were grown to $70-80 \%$ confluence in 6 -well culture plates in a DMEM/Opti-MEM medium (1:1) supplemented with 5\% fetal bovine serum (Gibco, Grand Island, NY, USA) in the presence 


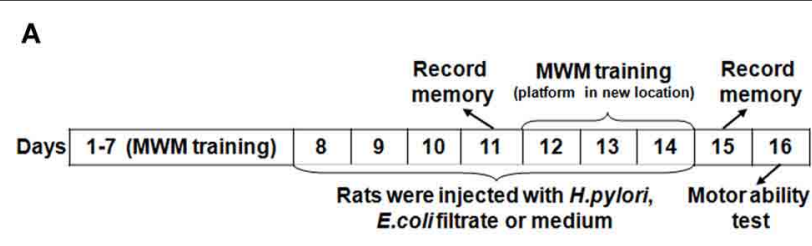

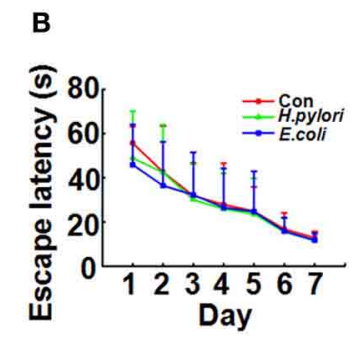

D

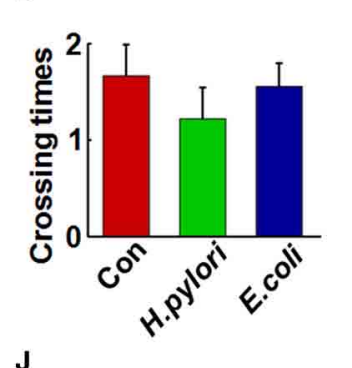

$$
\mathrm{J}
$$

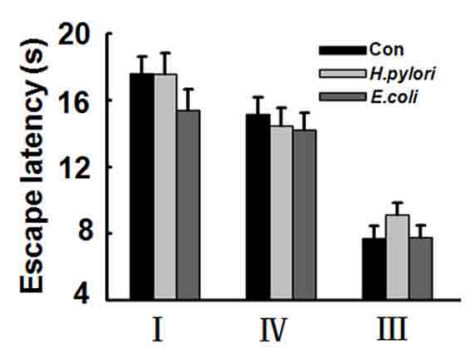

C

E
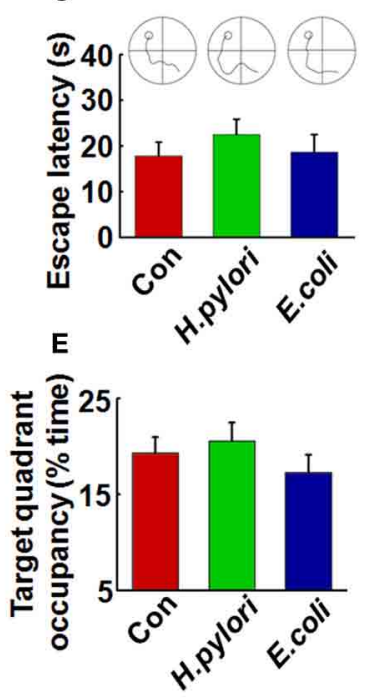

K

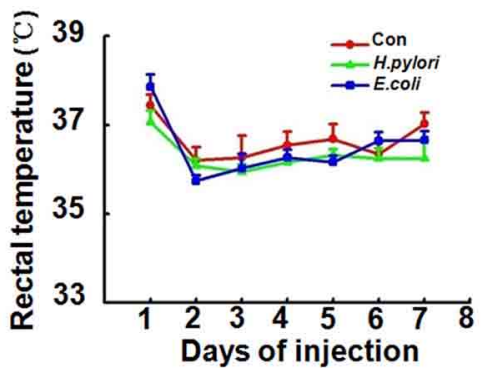

$\mathbf{F}$

H
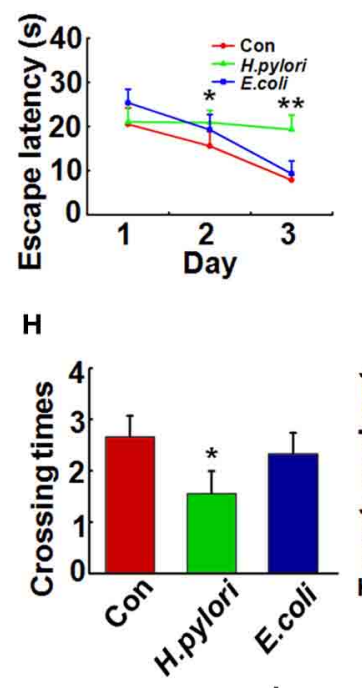

$\mathbf{L}$

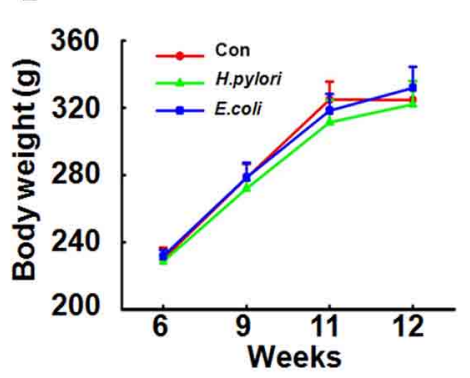

FIGURE 1 | Intraperitoneal injection of $\boldsymbol{H}$. pylori filtrate induces spatial learning and memory impairment in rats. (A) A schematic diagram for the treatment and behavior test of the rats. Thirty-four SD rats (male, $220 \pm 20 \mathrm{~g}$ ) were trained in Morris water maze (MWM) for 7 days, 27 rats which could find the hidden platform within $15 \mathrm{~s}$ at the end of training were selected and divided into three groups ( $n=9$ for each group) randomly. The rats were then intraperitoneally injected with $\mathrm{H}$. pylori, E.coli filtrate or DMEM/Opti-MEM medium ( $280 \mu \mathrm{l} / \mathrm{rat} / \mathrm{day})$ for 7 days. On day 11 of behavior test (day 4 of injection), the spatial memory of the rats in MWM was measured. The rats were then trained in MWM for another 3 days with altered location of the hidden platform (re-learning) for testing the spatial learning ability. On day 15 ( 1 day after the end of injection) the new spatial memory was measured. On day 16 the motor ability of the rats was detected by recording the escape latency to a visible platform in the MWM. At the end of behavior test, the rats were anesthetized and decapitated, and the hippocampal extracts or brain slices were prepared for further studies. (B) All the rats were trained to find the hidden platform within $15 \mathrm{~s}$ before the injection. (C-E) Intraperitoneal injection of $\mathrm{H}$. pylori filtrate for 3 days does not impair the formed spatial memory in MWM. The escape latency (C), number of crossing the platform (D) and the residence time in the target quadrant (E) were recorded on day 4 of injection, no difference was observed among different groups. (F-I) Intraperitoneal injection of $H$. pylori filtrate impairs the learning ability and memory of the rats in MWM with changed location of the platform. A new learning process was started on day 5 of injection, with the hidden platform placed in a new quadrant. Rat injected with $H$. pylori filtrate showed significantly extended latency in the second learning $(\mathbf{F})(p=0.033$, $F=2.439$ on new-learning day $2, p=0.001, F=6.387$ on new-learning day 3). On the testing day ( 1 day after the end of injection), the rats showed extended escape latency $(\mathbf{G})(p=0.016, F=4.526)$, decreased number of crossings $\mathbf{( H )}(p=0.034, F=3.39)$ and residence time in the target quadrant (I) $(p=0.005, F=4.858)$. The motor ability of the rats was tested in MWM with a visible platform in quadrant II, the latency of the rats from quadrant $\mathbf{I}$, III, and IV to the platform was recorded. The results displayed no difference among groups (J). The body temperature (K) and weight (L) of the rats also showed no differences among groups. ${ }^{*} p<0.05,{ }^{* *} p<0.01$ vs. control group (mean $\pm \mathrm{SD}, n=9$ ). of $200 \mathrm{mg} / \mathrm{L}$ G418 (Gibco, Grand Island, NY, USA). To minimize stress responses induced by serum deprivation, cells were switched to $0.5 \%$ fetal bovine serum media for 1 day, kept in fresh serum-free media for $2 \mathrm{~h}$. Then the cells were incubated with the prepared $H$. pylori filtrate, E.coli filtrate $(2 \mathrm{ml} /$ well $)$, or DMEM/Opti-MEM medium for $24 \mathrm{~h}$. At the end of incubation, all media were collected and centrifuged at $2000 \mathrm{~g}$ for $20 \mathrm{~min}$, the supernatants were stored at $-80^{\circ} \mathrm{C}$ for enzyme linked 
immunosorbent assay (ELISA); cells were rinsed twice in icecold PBS ( $\mathrm{pH} 7.5$ ) and collected, half of the cells were lysed with phosphate buffered saline ( $\mathrm{pH} 7.5$ ) containing $0.5 \mathrm{mM}$ PMSF and 1:1000 protease inhibitor cocktail (Sigma-Aldrich, St. Louis, MO, USA), repeatedly frozen and thawed for three times and centrifuged at $2000 \mathrm{~g}$ for $20 \mathrm{~min}$, the supernatants were collected and stored at $-80^{\circ} \mathrm{C}$ for ELISA; other half of the cells were lysed with buffer containing $2 \mathrm{mM}$ EGTA, $0.5 \mathrm{mM}$ PMSF, $5 \mathrm{mM}$ EDTA, $150 \mathrm{mM} \mathrm{NaCl}, 50 \mathrm{mM}$ Tris- $\mathrm{HCl}$ (pH 7.4), 1\% Triton X-100, and protease inhibitor cocktail (1:200), followed by sonication for 15 times on ice. The samples were stored at $-80^{\circ} \mathrm{C}$ for Western blotting.

\section{BRAIN TISSUE HOMOGENATE AND MEMBRANOUS PROTEIN EXTRACTION}

Rat hippocampus and cortex were isolated and homogenized in 10 volumes ( $\mathrm{ml} / \mathrm{g}$ wet tissue) homogenate buffer containing $50 \mathrm{mM}$ Tris- $\mathrm{HCl}, \mathrm{pH}$ 7.0, $0.5 \mathrm{mM}$ PMSF, $2.5 \mathrm{mM}$ EDTA, $2.5 \mathrm{mM}$ EGTA, $2.0 \mathrm{mM} \mathrm{Na} \mathrm{VO}_{4}, 100 \mathrm{mM} \mathrm{NaF}$ and 1:1000 protease inhibitor cocktail (Sigma-Aldrich, St. Louis, MO, USA). Then the homogenates were sonicated and stored at $-80^{\circ} \mathrm{C}$ for Western blotting. The membrane proteins were extracted by using the membrane protein extraction kit P0033 from Beyotime (Shanghai, China) according to the manufacturer's instruction.

\section{ELISA}

Sandwich ELISA was performed to measure the levels of $A \beta_{42}$ and $\mathrm{A} \beta_{40}$ both in rat brain extracts, N2a/APP cell lysates and media by using the human $A \beta_{42}$ ELISA kit E-EL-H0542 and human $\mathrm{A} \beta_{40}$ ELISA kit E-EL-H0543 (Elab, Wuhan, China) according to the manufacturer's instruction. Microplates were scanned with a microplate reader (Biotek, Winooski, VT, USA) set to $450 \mathrm{~nm}$.

\section{WESTERN BLOTTING}

The protein concentrations of the brain extracts and cell lysates were determined by BCA Protein Assay Kit (Thermo Fisher Scientific, Rockford, IL, USA). Then the samples were mixed with sample buffer containing $50 \mathrm{mM}$ Tris- $\mathrm{HCl}(\mathrm{pH} 7.6), 2 \%$ SDS, $10 \%$ glycerol, $10 \mathrm{mM}$ dithiothreitol, and $0.2 \%$ bromophenol blue and boiled for $5 \mathrm{~min}$. Boiled protein samples (15-20 $\mu \mathrm{g}$ per lane) were loaded and separated by $10 \%$ sodium dodecyl sulfate-polyacrylamide gel electrophoresis (SDS-PAGE), and then transferred to nitrocellulose membranes. The membranes were detected by using anti-rabbit or anti-mouse IgG conjugated to IRDye (800CW; Li-cor Biosciences, Lincoln, NE, USA) for $1 \mathrm{~h}$ at room temperature and visualized using the Odyssey Infrared Imaging System (Li-cor Biosciences, Lincoln, NE, USA). The protein bands were quantitatively analyzed by Kodak Digital Science 1D software (Eastman Kodak Company, New Haven, CT, USA).

\section{STATISTICAL ANALYSIS}

Data are expressed as mean \pm SD and analyzed using SPSS 16.0 statistical software (SPSS Inc., Chicago, IL, USA). The One-Way analysis of variance (ANOVA) procedure followed by LSD's posthoc tests was used to determine the differences among groups, $p<0.05$ was considered as significant, $p<0.01$ was considered as very significant.

\section{RESULTS \\ H. PYLORI FILTRATE INDUCES SPATIAL LEARNING AND MEMORY IMPAIRMENT IN RATS}

To evaluate the effect of $H$. pylori infection on learning and memory in vivo, we first trained the 3 -month-old SD rats $(n=34)$ in the water maze for 7 consecutive days, then selected the rats $(n=$ 27) which learned to find the hidden platform within $15 \mathrm{~s}$ for the following bacterial filtrates injection and detection (Figure 1A). As it was shown in Figure 1B, 27 rats which were able to find the hidden platform within $15 \mathrm{~s}$ were randomly divided into three groups ( $n=9$ for each group), each group showed the similar spatial learning and memory before the bacterial filtrates injection. Intraperitoneal injection of $H$. pylori filtrate for 3 days did not influence the formed spatial memory in the MWM before the injection (Figures 1C-E). But in a following new spatial learning task, compared with the controls, rats injected with $H$. pylori filtrate showed significantly prolonged latency in searching the hidden platform in a new quadrant, indicating an impaired spatial learning ability in the rats (Figure 1F, $p=0.033, F=2.439$ on new-learning day 2, $p=0.001, F=6.387$ on new-learning day 3). At the end of injection, the spatial memory for the new learning was test, rats injected with $H$. pylori filtrate for 7 days showed increased escape latency (Figure 1G, $p=0.016, F=$ $4.526)$, reduced crossing times and target quadrant occupancy compared with control and E.coli filtrate-injected rats (Figure $\mathbf{1 H}$, $p=0.034, F=3.39$; Figure 1I, $p=0.005, F=4.858)$. These data identified that $H$. pylori filtrate impairs spatial learning and memory. When the rats were trained to find a visible platform, they showed indistinguishable latency in the MWM (Figure 1J), indicating that the spatial learning and memory deficit in the $H$. pylori filtrate-injected rats is not caused by altered motivation or ability to learn explicit information. The body temperature and weight of the animals showed no difference among the groups (Figures 1K,L). In a summary, these behavior testing results suggest that intraperitoneal injection $H$. pylori filtrate induces spatial learning and memory deficit in rats.

\section{INTRAPERITONEAL INJECTION OF $\boldsymbol{H}$. PYLORI FILTRATE CAUSES A $\beta_{42}$ ELEVATION IN RAT BRAINS}

To explore the mechanisms underlying the spatial learning and memory deficit, we first detected whether there was a neuronal loss in the rat brains. Nissl staining of the neurons showed comparable cell number and density in the hippocampus and cortex of the rat brains in all the three groups (Figure 2), indicating that the learning and memory impairment in $H$. pylori filtrateinjected rats is induced by disturbed neuronal function but not by neuron loss. $\mathrm{A} \beta$ level is increased in $\mathrm{AD}$ brains and induces cognitive deficits in AD animal models (Billings et al., 2005; Liu et al., 2013). To further disclose the underlying mechanisms for memory deficit induced by $H$. pylori filtrate, we detected the $\mathrm{A} \beta_{40}$ and $A \beta_{42}$ levels in the rat brains. The results showed that $H$. pylori filtrate injection induced $A \beta_{42}$ elevation both in the hippocampus (Figure 3A, $p=0.002, F=20.142$ ) and cortex (Figure 3B, $p=$ $0.045, F=16.637$ ), with no effect on $A \beta_{40}$ levels (Figures 3C,D). Compared with $A \beta_{40}, A \beta_{42}$ is more toxic and specifically induces memory impairment in water maze and passive avoidance tests in mice (Jhoo et al., 2004), thus, H. pylori filtrate may cause learning 


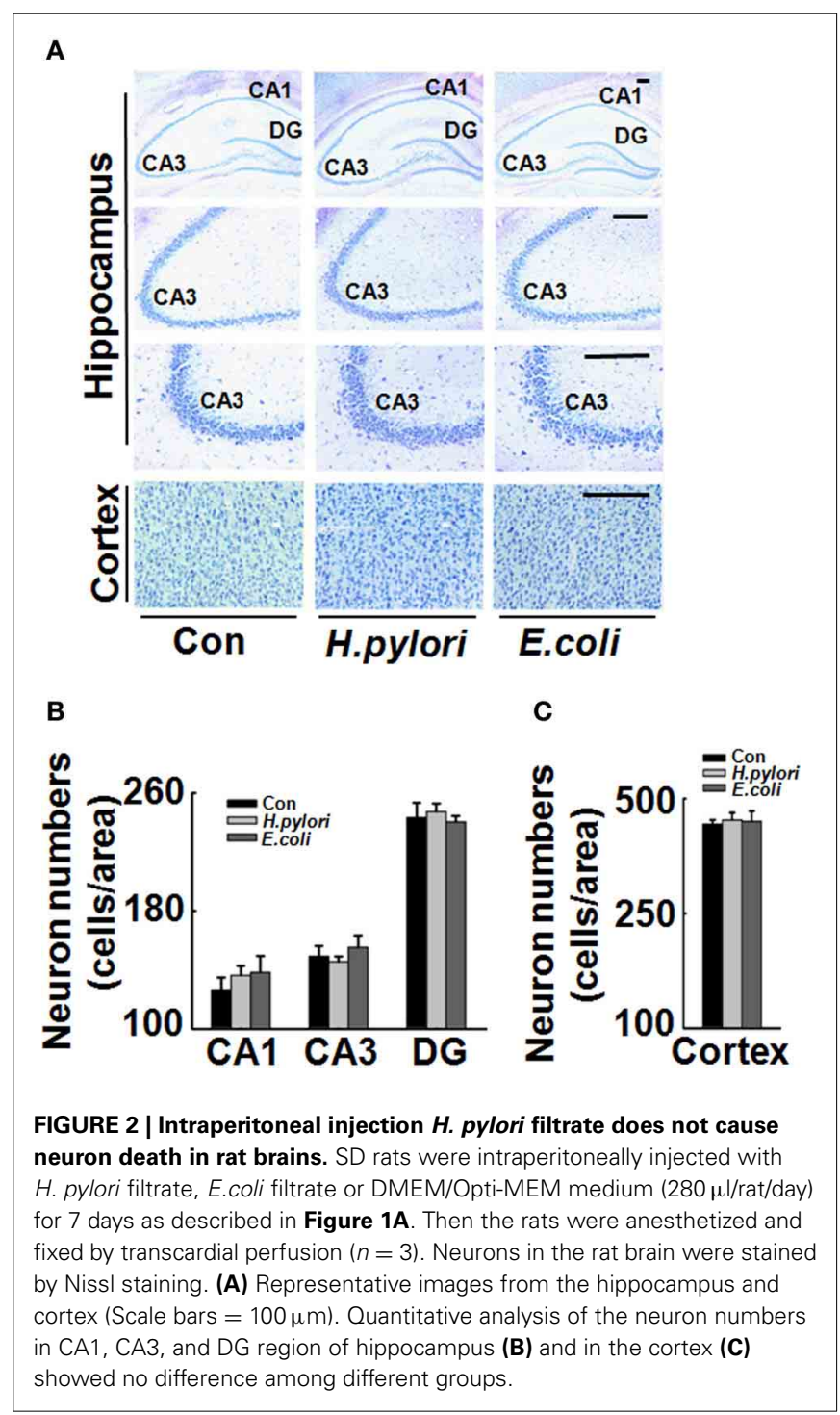

and memory deficit through enhancing $A \beta_{42}$ production in rat brains.

\section{INTRAPERITONEAL INJECTION OF H. PYLORI FILTRATE IMPAIRS THE DENDRITIC SPINE MATURATION AND REDUCES MEMBRANE EXPRESSION OF SYNAPTIC PROTEINS IN RAT HIPPOCAMPUS}

Impairment of synaptic plasticity contributes to learning and memory deficit. $A \beta$ peptides may disrupt hippocampal synaptic plasticity via altered NMDA or AMPA receptor-PSD-MAGUK interactions (Proctor et al., 2011). Given this, we predict that $H$. pylori filtrate-induced $A \beta_{42}$ elevation may cause learning and memory deficit through disturbing synaptic plasticity. To confirm this hypothesis, we observed the density and morphology of dendritic spines in the dentate gyrus of the hippocampus, one critical brain region involved in spatial learning and memory (Kesner, 2013). H. pylori filtrate-injected rats showed no difference of the total spine numbers compared with the other two groups, but the mature mushroom spines were significantly reduced

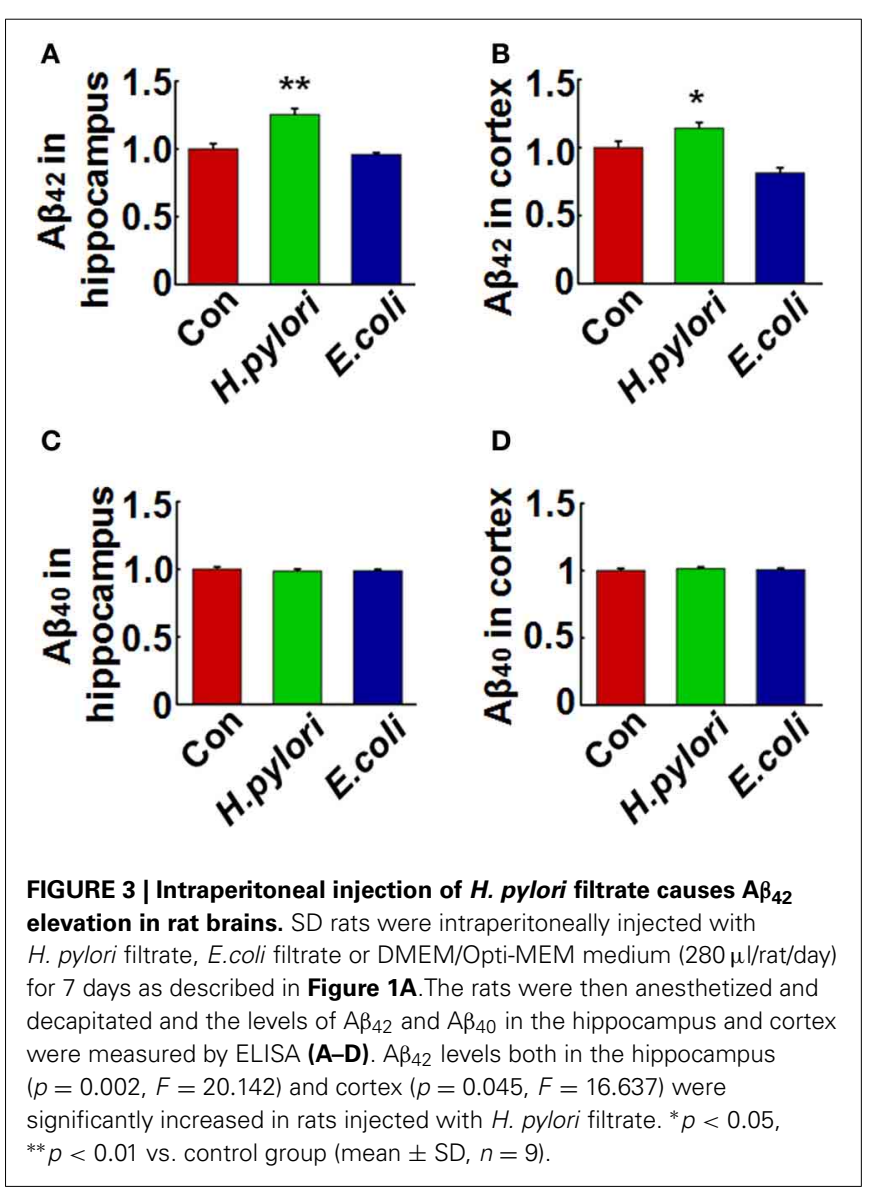

(Figure 4, $p=0.0003, F=45.103$ ). Correspondingly, the membrane expression of functional synaptic receptors and scaffolding proteins such as NMDA-NR2A, NR2B, PSD-93, and PSD-95 was remarkably decreased in the hippocampus (Figures 5C,D, NR2A, $p=0.001, F=21.32$; NR2B, $p=0.008, F=13.808$; PSD-93, $p=0.002, F=13.189$; PSD-95, $p=0.001, F=18.183$ ), the total protein level of PSD-93 was also decreased in the H. pylori filtrate treated group (Figures 5A,B, $p=0.004, F=10.015$ ). These results suggest that $H$. pylori filtrate may induce cognitive deficit through disrupting synaptic plasticity.

\section{H. PYLORI FILTRATE INCREASES A $\beta_{42}$ PRODUCTION BY ENHANCING THE EXPRESSION OF $\gamma$-SECRETASE}

$A \beta$ is released from the precursor protein APP through the cleavage of $\beta$ and $\gamma$-secretase. To explore the mechanisms underlying the $H$. pylori-induced $A \beta$ production, we test the expression of BACE-1, PS-1, and PS-2 in rat brains. We found that the protein level of PS-2, the key component of $\gamma$-secretase, was significantly increased in $H$. pylori filtrate-injected rat hippocampus (Figures 6A,B, $p=0.012, F=8.24$ ) and cortex (Figures 6C,D, $p=0.004, F=10.868$ ) while the BACE-1 and PS-1 levels remained unchanged (Figure 6). These data indicate that $H$. pylori filtrate may promote the $A \beta_{42}$ production by enhancing the activity of $\gamma$-secretase. To further confirm this speculation, N2a cells stably over-expressing APP (N2a/APP) were incubated with $H$. pylori or E.coli filtrate for $24 \mathrm{~h}$, then the 

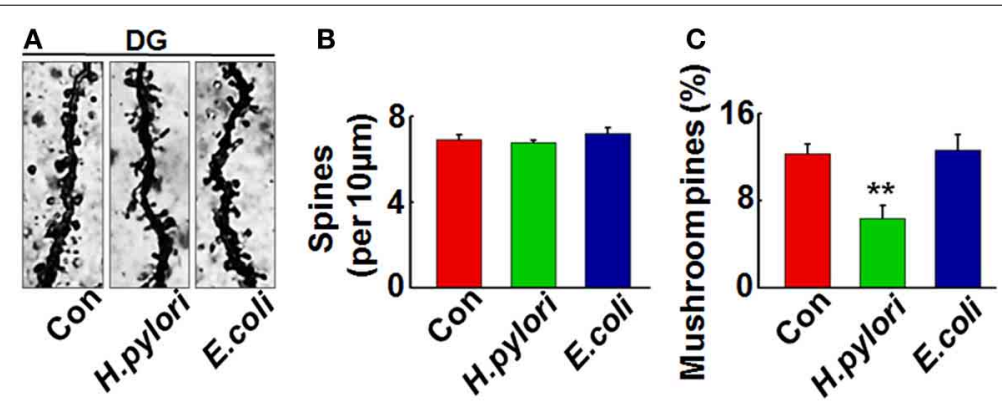

FIGURE 4 | Intraperitoneal injection of $\boldsymbol{H}$. pylori filtrate impairs the dendritic spine maturation in rat hippocampal dentate gyrus. SD rats were intraperitoneally injected with $H$. pylori filtrate, E.coli filtrate or DMEM/Opti-MEM medium (280 $\mu \mathrm{l} / \mathrm{rat} /$ day) for 7 days as described in Figure 1A. Three rats were then anesthetized and fixed by transcardial perfusion, and brain slices of the rats were stained by Golgi staining. (A) The representative images of dendritic spines in the hippocampal dentate gyrus. Quantitative analysis of the spine density (calculated as the average number of spines per $10 \mu \mathrm{m}$ on the dendrites) showed no difference among the groups (B), while the percentage of mushroom spines were significantly decreased in rats injected with $H$. pylori filtrate (C) $(p=0.0003, F=45.103)$. ** $p<0.01$ vs. control group (mean $\pm \mathrm{SD}, n=3$ ).
$\mathrm{A} \beta$ levels, expression of $\beta$, and $\gamma$-secretase were detected. The results showed that $H$. pylori filtrate incubation directly increased intracellular $\mathrm{A} \beta_{42}$ level (Figure 7A, $p=0.001, F=25.087$ ) and promoted $A \beta_{42}$ release into the culture media (Figure $7 \mathbf{B}, p=$ $0.002, F=29.247)$, with a simultaneous up-regulation of PS2 in cells (Figures 7E,F, $p=0.001, F=22.92$ ). No significant change of $A \beta_{40}$ levels was observed among the different groups (Figures 7C,D). Thus, soluble exotoxins, or surface proteins released from the $H$. pylori bacteria may directly promote $\mathrm{A} \beta_{42}$ production and release by enhancing the activity of $\gamma$-secretase.

\section{DISCUSSION}

As the most common type of dementia, $\mathrm{AD}$ affects more than 35 million people in the world. The vast majority of $\mathrm{AD}$ cases are sporadic, implying that environmental factors are more causative in the disease development. H. pylori, a curved, spiral-shaped, gram-negative bacterium chronically colonizing in the stomach, has been linked to AD based on clinical surveys and investigations (Malaguarnera et al., 2004; Kountouras et al., 2007a), but the direct laboratory evidence is still lacking. In the present study, we demonstrated that $H$. pylori filtrate could induce AD-like cognitive deficit and $A \beta_{42}$ overproduction possibly through enhancing the activity of $\gamma$-secretase.

H. pylori infection was first related to $\mathrm{AD}$ in a study performed by Malaguarnera et al. In this study, they reported a higher seropositivity for anti-H. pylori immunoglobulin $\mathrm{G}$ antibodies in 30 patients with $\mathrm{AD}$ than in 30 age-matched controls (Malaguarnera et al., 2004). In a later investigation by Kountouras et al., a higher prevalence of $H$. pylori infection in $50 \mathrm{AD}$ patients than in 30 anemic controls was reported (Kountouras et al., 2006). Then they further observed increased H. pylori antibody in cerebrospinal fluid in AD (Kountouras et al., 2009a). In the following, two independent clinic studies indicated that $H$. pylori eradication regimen in $\mathrm{AD}$ patients was associated with decreased progression of dementia and a higher 5-year survival rate (Kountouras et al., 2010; Chang et al., 2013). On the other side, AD patients with $H$. pylori infection showed worse performance in cognition test and increased disease markers such as total/phosphorylated tau and cytokines in CSF compared with
AD patients without $H$. pylori infection (Roubaud-Baudron et al., 2012; Beydoun et al., 2013). Thus, H. pylori may be one of the infectious etiologies of $\mathrm{AD}$. However, till now the direct laboratory evidence that $H$. pylori are cause of $\mathrm{AD}$ is still lacking. One possible reason is that $H$. pylori infection may induce gastritis and peptic ulcer, which further cause hyperhomocysteinemia (Santarelli et al., 2004; Evrengul et al., 2007), the latter is related with a high risk of $\mathrm{AD}$ (Seshadri et al., 2002; Morris, 2003). H. pylori infection also results in the onset or progression of extradigestive disorders, such as polyradiculoneuropathy, hypertension, cardiovascular, and/or cerebrovascular ischemia, and stroke (Mendall et al., 1994; Blaser and Atherton, 2004; Kountouras et al., 2005; Sawayama et al., 2005). Most of these complications have been linked to $\mathrm{AD}$. Thus, it is difficult to evaluate the direct effect of the bacteria per se on $\mathrm{AD}$ development. In the present study, through intraperitoneal injection of $H$. pylori filtrate, i.e., soluble surface fractions or other exotoxins secreted from the bacteria, we explored the effect of $H$. pylori on cognition and $\mathrm{AD}$-like amyloidosis in rats.

$\mathrm{AD}$ patients first exhibit spatial learning and memory deficit in the progression of cognitive impairments. In our experiment, we found that intraperitoneal injection of $H$. pylori filtrate for 3 days did not interrupt the formed spatial memory in MWM. $H$. pylori is a bacterium chronically colonized to the stomach of the patient, the effect of $H$. pylori on the brain may also occur in a long time. We speculated a longer treatment may induce a difference. Thus, we prolonged the injection to 7 days, and trained the rats in MWM with changed location of the hidden platform. In the following new spatial learning, rats injected with $H$. pylori filtrate showed impaired performance compared with control rats. In a test of the newly-formed memory at the end of the training, these rats also exhibited worse memory ability compared with controls. To exclude the possibility that $H$. pylori filtrate may influence the performance of the rats in water maze through unspecific effects such as fever, decreased food intake, or impairment of the motor ability, we detected the body weight, temperature, and escape latency of the rats to find a visible platform in the water maze, no difference was observed among the different groups. Furthermore, rats 


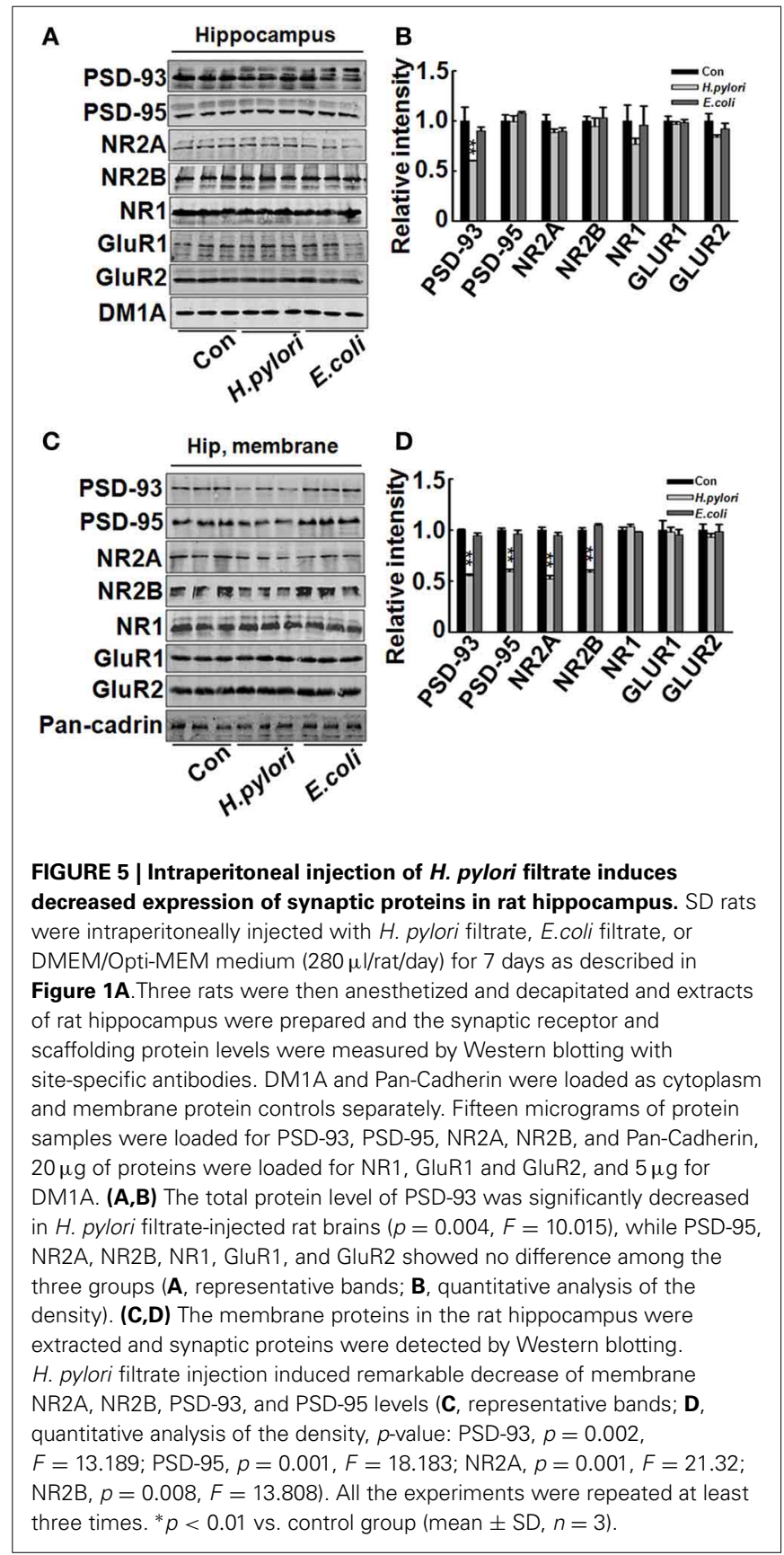

injected with comparable concentration of E.coli filtrate did not show learning and memory deficit, suggesting that the effect of H. pylori filtrate on cognition is specific. Several clinic investigations have reported that the severity of $H$. pylori infection is correlated with cognitive performance of the normal adults and MCI (mild cognitive impairment, a prodromal phase of $\mathrm{AD}$ ) patients (Kountouras et al., 2007b; Beydoun et al., 2013), and eradication of $H$. pylori is associated with decreased progression of dementia (Kountouras et al., 2009b; Chang et al., 2013) in AD patients. Our study provided the first laboratory evidence that $H$. pylori could induce AD-like spatial learning and memory impairment.

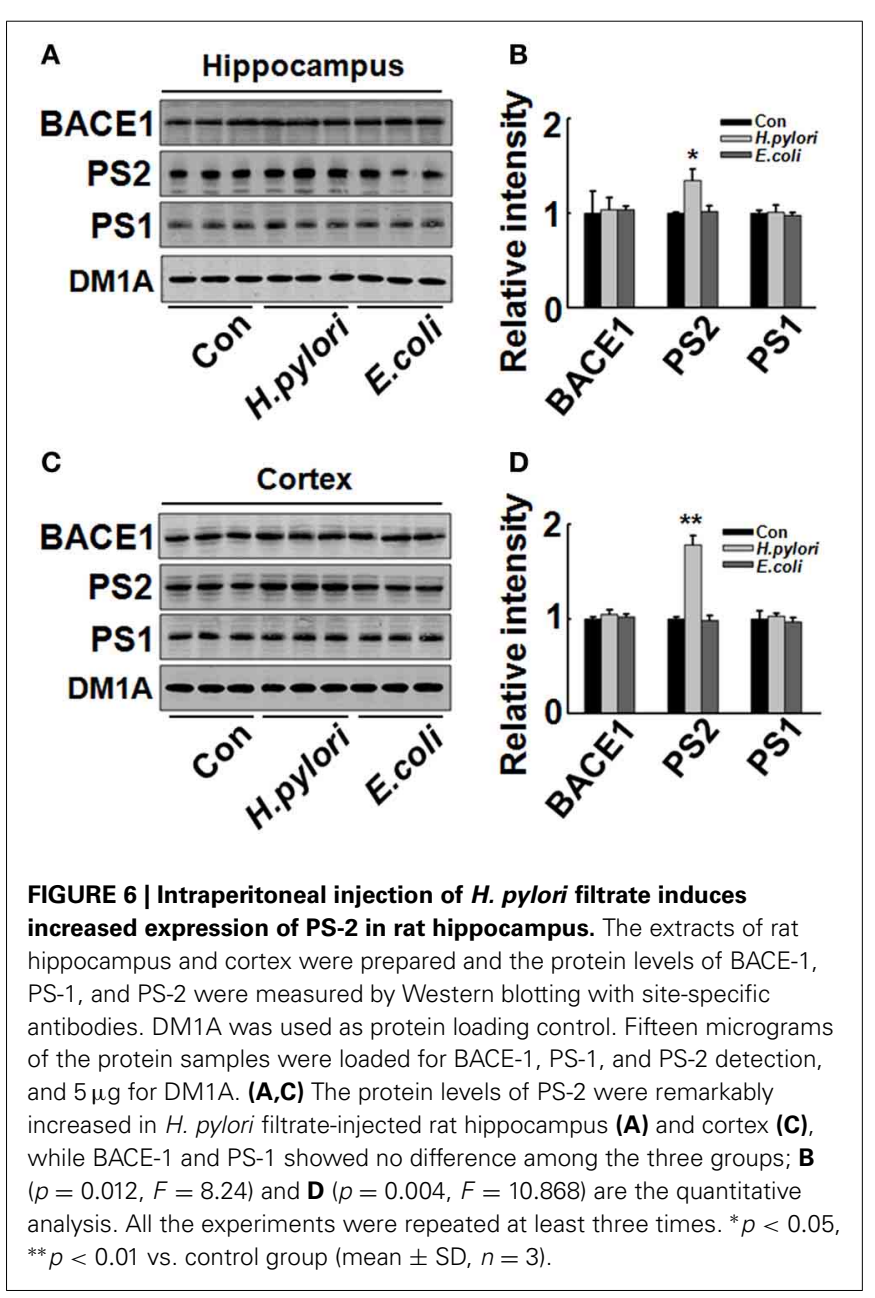

To disclose the underlying mechanism for the behavior deficit, we detected the neuronal numbers in hippocampus and cortex, two brain regions responsible for spatial learning and memory. No change was observed in the rats injected with $H$. pylori filtrate, indicating that $H$. pylori did not induce neuronal death. Thus, the learning and memory impairment in $H$. pylori filtrate-injected rats may be resulted from disturbance of neuronal function. $A \beta$ level is increased in $\mathrm{AD}$ brains and induces cognitive deficit in $\mathrm{AD}$ animal models (Billings et al., 2005; Liu et al., 2013). Considering the correlation of $H$. pylori infection and $\mathrm{AD}$, we suspect that $H$. pylori may increase the production of $\mathrm{A} \beta$, and then promote the cognitive dysfunction. To test this hypothesis, we detected $A \beta_{40}$ and $A \beta_{42}$ levels both in the hippocampus and cortex of the rats. A significant elevation of $A \beta_{42}$ was observed in hippocampus and cortex of the rats injected with $H$. pylori filtrate. Compared with $A \beta_{40}, A \beta_{42}$ is more easily to form aggregates (Jarrett et al., 1993), and more toxic to neurons (Zhang et al., 2002). Intracerebroventricular injection of $A \beta_{42}$ induces memory impairment in water maze and passive avoidance tests in mice (Jhoo et al., 2004). In $\mathrm{AD}$ transgenic mice, $\mathrm{A} \beta_{42}$ increases to a higher level than $A \beta_{40}$ and correlates with the cognitive deficits (Hsiao et al., 1996; Billings et al., 2005). More importantly, intracellular $A \beta_{42}$ but not $A \beta_{40}$ accumulation in $A D$-vulnerable brain 


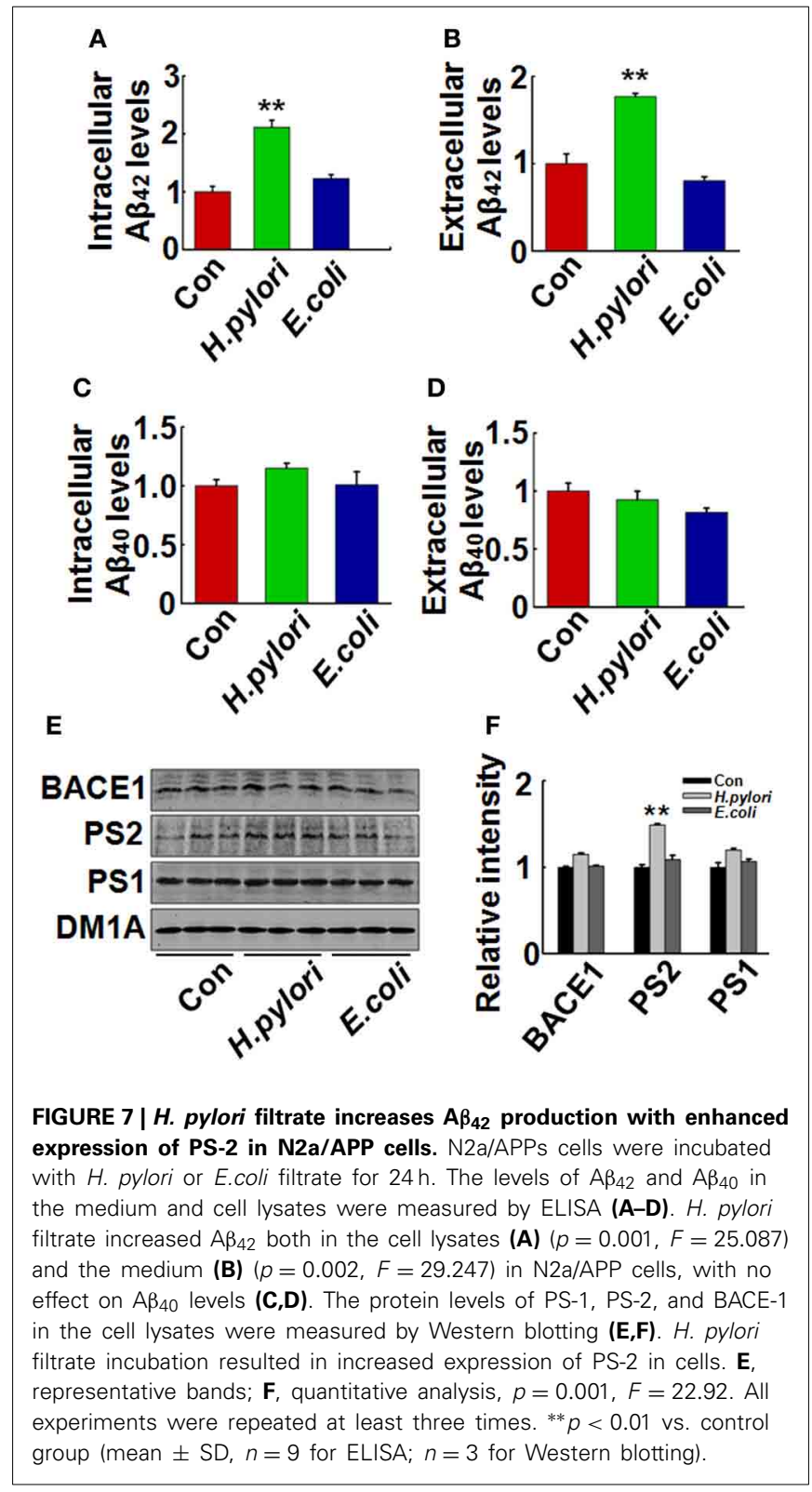

regions is an early event preceded both NFT and plaque deposition (Iwatsubo et al., 1994; Gouras et al., 2000). Thus, peripheral $H$. pylori infection may cause learning and memory deficit through enhancing $A \beta_{42}$ production in rat brains. Consistent with the behavior deficits, retarded dendritic spine maturation, and decreased membrane expression of learning/memory related synaptic receptors and scaffolding proteins were observed in $H$. pylori-injected rats. $\mathrm{A} \beta$ peptides may disrupt hippocampal synaptic plasticity via altered NMDA or AMPA receptor-PSD-MAGUK interactions (Proctor et al., 2011), these data further confirmed our speculation that $H$. pylori filtrate causes cognitive damage through $\mathrm{A} \beta_{42}$.

$\mathrm{A} \beta$ is formed by sequential cleavage of APP by $\beta$ and $\gamma$-secretase (Selkoe, 1998). To explore the mechanisms underlying the $H$. pylori-induced $\mathrm{A} \beta$ elevation, we detected the expression levels of key functional proteins in $\beta$ and $\gamma$-secretase such as BACE-1, PS-1, and PS-2. A significant increase of PS-2 in H. pylori filtrate-injected rat hippocampus and cortex was observed, indicating that $H$. pylori filtrate may promote $A \beta_{42}$ production by enhancing the activity of $\gamma$-secretase. Enhanced cleavage of APP by $\gamma$-secretase is the key event inducing $A \beta$ overproduction; inhibiting the $\gamma$-secretase is considered to be the leading amyloidbased approach to preventing AD (Selkoe, 1998). In familial early-onset $\mathrm{AD}$, more than 50 missense mutations in PS- 1 and PS-2 have been found, and they selectively increase the production of $\mathrm{A} \beta_{42}$ (Citron et al., 1997; Xia et al., 1997; Qi et al., 2003). In our experiment, $H$. pylori filtrate injection resulted in increased $\mathrm{A} \beta_{42}$ production and PS- 2 expression, strongly indicating that $H$. pylori could promote amyloidosis partially through targeting PS-2. To further confirm this hypothesis, we incubated N2a/APP cells with $H$. pylori filtrate directly, and observed the same results: $H$. pylori filtrate incubation not only increased intracellular $A \beta_{42}$ level but also promoted $A \beta_{42}$ release, with a simultaneous up-regulation of PS-2 in cells. Thus, soluble exotoxins, or surface proteins released from the $H$. pylori bacteria may directly promote $A \beta_{42}$ production and release by enhancing the activity of $\gamma$-secretase. The precise mechanisms for how the soluble surface fractions of $H$. pylori get into the brain and influence the neurons need further investigation. Furthermore, which component in the $H$. pylori filtrate contributes to the above described effects also needs further exploration. Another possibility is that $H$. pylori filtrate may induce a peripheral inflammatory response such as production of cytokines; the latter may further initiate the pathological changes in the brain. But in our recent study (in revision), two cytokines (TNF- $\alpha$ and IL-8) which were identified to be increased in AD plasma (RoubaudBaudron et al., 2012) showed no change in $H$. pylori filtrateinjected rats. Thus, other inflammatory mechanisms should be explored.

In a summary, we have found in the present study that injection of $H$. pylori filtrate increases $A \beta_{42}$ production with elevated expression of PS-2. H. pylori filtrate leads to spatial learning and memory deficits in the rats, and impairs the synaptic maturation. Our data have provided molecular evidence to disclose the intrinsic link between $H$. pylori infection and $\mathrm{AD}$-like $\mathrm{A} \beta$ overproduction and memory impairments.

\section{AUTHOR CONTRIBUTIONS}

Conception of the research: Ji Zeng and Rong Liu. Performing experiments: Xiu-Lian Wang, Ji Zeng, Jin Feng, Yi-Tao Tian, YuJian Liu, Mei Qiu, Xiong Yan, Yang Yang, and Qun Wang. Analyses and interpretation of results: Yan Xiong, Zhi-Hua Zhang, JianZhi Wang, and Rong Liu. Drafting of the manuscript: Xiu-Lian Wang. Critical revision of the manuscript: Rong Liu, Ji Zeng, and Jian-Zhi Wang.

\section{ACKNOWLEDGMENTS}

We thank Dr. Pei Jin-jing (Karolinska Institutet, Sweden) for N2a/APP cell line, and Dr. Zhu Liang-ru (Union Hospital, Huazhong University of Science and Technology) for H. pylori strain. This work was supported by the National Natural Science Foundation of China (No: 81271403, 81261120570), and the 
Fundamental Research Funds for the Central Universities, HUST (No: 2012QN133).

\section{REFERENCES}

Beydoun, M. A., Beydoun, H. A., Shroff, M. R., Kitner-Triolo, M. H., and Zonderman, A. B. (2013). Helicobacter pylori seropositivity and cognitive performance among US adults: evidence from a large national survey. Psychosom. Med. 75, 486-496. doi: 10.1097/PSY.0b013e31829108c3

Billings, L. M., Oddo, S., Green, K. N., McGaugh, J. L., and LaFerla, F. M. (2005). Intraneuronal Abeta causes the onset of early Alzheimer's diseaserelated cognitive deficits in transgenic mice. Neuron 45, 675-688. doi: 10.1016/j.neuron.2005.01.040

Blaser, M. J., and Atherton, J. C. (2004). Helicobacter pylori persistence: biology and disease. J. Clin. Invest. 113, 321-333. doi: 10.1172/JCI200420925

Borchelt, D. R., Thinakaran, G., Eckman, C. B., Lee, M. K., Davenport, F., Ratovitsky, T., et al. (1996). Familial Alzheimer's disease-linked presenilin 1 variants elevate Abeta1-42/1-40 ratio in vitro and in vivo. Neuron 17,1005-1013. doi: 10.1016/S0896-6273(00)80230-5

Braak, H., and Braak, E. (1992). The human entorhinal cortex: normal morphology and lamina-specific pathology in various diseases. Neurosci. Res. 15, 6-31. doi: 10.1016/0168-0102(92)90014-4

Busciglio, J., Lorenzo, A., Yeh, J., and Yankner, B. A. (1995) Beta-amyloid fibrils induce tau phosphorylation and loss of microtubule binding. Neuron 14, 879-888. doi: 10.1016/0896-6273(95)90232-5

Chang, Y. P., Chiu, G. F., Kuo, F. C., Lai, C. L., Yang, Y. H., Hu, H. M., et al. (2013). Eradication of Helicobacter pylori is associated with the progression of dementia: a population-based study. Gastroenterol. Res. Pract. 2013:175729. doi: $10.1155 / 2013 / 175729$

Citron, M., Westaway, D., Xia, W., Carlson, G., Diehl, T., Levesque, G. et al. (1997). Mutant presenilins of Alzheimer's disease increase production of 42-residue amyloid beta-protein in both transfected cells and transgenic mice. Nat. Med. 3, 67-72. doi: 10.1038/nm0197-67

Duff, K., Eckman, C., Zehr, C., Yu, X., Prada, C. M., Perez-tur, J., et al. (1996). Increased amyloid-beta42(43) in brains of mice expressing mutant presenilin 1. Nature 383, 710-713. doi: 10.1038/383710a0

Evrengul, H., Tanriverdi, H., Kuru, O., Enli, Y., Yuksel, D., Kilic, A., et al. (2007). Elevated homocysteine levels in patients with slow coronary flow: relationship with Helicobacter pylori infection. Helicobacter 12, 298-305. doi: 10.1111/j.15235378.2007.00505.x

Gouras, G. K., Tsai, J., Naslund, J., Vincent, B., Edgar, M., Checler, F., et al. (2000). Intraneuronal Abeta42 accumulation in human brain. Am. J. Pathol. 156, 15-20. doi: 10.1016/S0002-9440(10)64700-1

Harada, J., and Sugimoto, M. (1999).Activation of caspase-3 in beta-amyloidinduced apoptosis of cultured rat cortical neurons. Brain Res. 842, 311-323. doi: 10.1016/S0006-8993(99)01808-9

Hsiao, K., Chapman, P., Nilsen, S., Eckman, C., Harigaya, Y., Younkin, S., et al. (1996). Correlative memory deficits, Abeta elevation, and amyloid plaques in transgenic mice. Science 274, 99-102. doi: 10.1126/science.274.5284.99

Iwatsubo, T., Odaka, A., Suzuki, N., Mizusawa, H., Nukina, N., and Ihara, Y. (1994). Visualization of A beta 42(43) and A beta 40 in senile plaques with end-specific A beta monoclonals: evidence that an initially deposited species is A beta $42(43)$. Neuron 13, 45-53. doi: 10.1016/0896-6273(94)90458-8

Jarrett, J. T., Berger, E. P., and Lansbury, P. J. Jr. (1993). The carboxy terminus of the beta amyloid protein is critical for the seeding of amyloid formation: implications for the pathogenesis of Alzheimer's disease. Biochemistry 32, 4693-4697. doi: 10.1021/bi00069a001

Jhoo, J. H., Kim, H. C., Nabeshima, T., Yamada, K., Shin, E. J., Jhoo, W. K., et al. (2004). Beta-amyloid (1-42)-induced learning and memory deficits in mice: involvement of oxidative burdens in the hippocampus and cerebral cortex. Behav. Brain Res. 155, 185-196. doi: 10.1016/j.bbr.2004.04.012

Keates, S., Keates, A. C., Warny, M., Peek, R. J., Murray, P. G., and Kelly, C. P. (1999). Differential activation of mitogen-activated protein kinases in AGS gastric epithelial cells by cag+ and cag- Helicobacter pylori. J. Immunol. 163, 5552-5559.

Kesner, R. P. (2013). An analysis of the dentate gyrus function. Behav. Brain Res. 254, 1-7. doi: 10.1016/j.bbr.2013.01.012.

Kountouras, J., Boziki, M., Gavalas, E., Zavos, C., Deretzi, G., Chatzigeorgiou, S., et al. (2010). Five-year survival after Helicobacter pylori eradication in Alzheimer disease patients. Cogn. Behav. Neurol. 23, 199-204. doi: 10.1097/WNN.0b013e3181df3034

Kountouras, J., Boziki, M., Gavalas, E., Zavos, C., Deretzi, G., Grigoriadis, N., et al. (2009a). Increased cerebrospinal fluid Helicobacter pylori antibody in Alzheimer's disease. Int. J. Neurosci. 119, 765-777. doi: 10.1080/00207450902782083

Kountouras, J., Boziki, M., Gavalas, E., Zavos, C., Grigoriadis, N., Deretzi, G., et al. (2009b). Eradication of Helicobacter pylori may be beneficial in the management of Alzheimer's disease. J. Neurol. 256, 758-767. doi: 10.1007/s00415-009-5011-z

Kountouras, J., Deretzi, G., Zavos, C., Karatzoglou, P., Touloumis, L., Nicolaides, T., et al. (2005). Association between Helicobacter pylori infection and acute inflammatory demyelinating polyradiculoneuropathy. Eur. J. Neurol. 12, 139-143. doi: 10.1111/j.1468-1331.2004.00977.x

Kountouras, J., Gavalas, E., Zavos, C., Stergiopoulos, C., Chatzopoulos, D., Kapetanakis, N., et al. (2007a). Alzheimer's disease and Helicobacter pylori infection: defective immune regulation and apoptosis as proposed common links. Med. Hypotheses 68, 378-388. doi: 10.1016/j.mehy.2006.06.052

Kountouras, J., Tsolaki, M., Boziki, M., Gavalas, E., Zavos, C., Stergiopoulos, C., et al. (2007b). Association between Helicobacter pylori infection and mild cognitive impairment. Eur. J. Neurol. 14, 976-982. doi: 10.1111/j.14681331.2007.01827.x

Kountouras, J., Tsolaki, M., Gavalas, E., Boziki, M., Zavos, C., Karatzoglou, P., et al. (2006). Relationship between Helicobacter pylori infection and Alzheimer disease. Neurology. 66, 938-940. doi: 10.1212/01.wnl.0000203644.68059.5f

Li, S., Hong, S., Shepardson, N. E., Walsh, D. M., Shankar, G. M., and Selkoe, D. (2009). Soluble oligomers of amyloid Beta protein facilitate hippocampal longterm depression by disrupting neuronal glutamate uptake. Neuron 62, 788-801. doi: 10.1016/j.neuron.2009.05.012

Lithfous, S., Dufour, A., and Després, O. (2013). Spatial navigation in normal aging and the prodromal stage of Alzheimer's disease: insights from imaging and behavioral studies. Ageing Res. Rev. 12, 201-213. doi: 10.1016/j.arr.2012.04.007

Liu, X. J., Yuan, L., Yang, D., Han, W. N., Li, Q. S., Yang, W., et al. (2013). Melatonin protects against amyloid-beta-induced impairments of hippocampal LTP and spatial learning in rats. Synapse 67, 626-636. doi: 10.1002/syn.21677

Malaguarnera, M., Bella, R., Alagona, G., Ferri, R., Carnemolla, A., and Pennisi, G. (2004). Helicobacter pylori and Alzheimer's disease: a possible link. Eur. J. Intern. Med. 15, 381-386. doi: 10.1016/j.ejim.2004.05.008

Mattson, M. P., Tomaselli, K. J., and Rydel, R. E. (1993). Calcium-destabilizing and neurodegenerative effects of aggregated beta-amyloid peptide are a-tenuated by basic FGF. Brain Res. 621, 35-49. doi: 10.1016/0006-8993(93)90295-X

Mendall, M. A., Goggin, P. M., Molineaux, N., Levy, J., Toosy, T., Strachan, D., et al. (1994) Relation of Helicobacter pylori infection and coronary heart disease. $B r$. Heart J. 71, 437-439. doi: 10.1136/hrt.71.5.437

Morris, M. S. (2003) Homocysteine and Alzheimer's disease. Lancet Neurol. 2, 425-428. doi: 10.1016/S1474-4422(03)00438-1

Morris, R. (1984). Developments of a water-maze procedure for studying spatial learning in the rat. J. Neurosci. Methods 11, 47-60. doi: 10.1016/01650270(84)90007-4

Muller, D., Nikonenko, I., Jourdain, P., and Alberi, S. (2002). LTP, memory and structural plasticity. Curr. Mol. Med. 2, 605-611. doi: 10.2174/1566524023362041

Ohkusa, T., Okayasu, I., Miwa, H., Ohtaka, K., Endo, S., and Sato, N. (2003). Helicobacter pylori infection induces duodenitis and superficial duodenal ulcer in Mongolian gerbils. Gut 52, 797-803. doi: 10.1136/gut.52.6.797

Proctor, D. T., Coulson, E. J., and Dodd, P. R. (2011). Post-synaptic scaffolding protein interactions with glutamate receptors in synaptic dysfunction and Alzheimer's disease. Prog. Neurobiol. 93, 509-521. doi: 10.1016/j.pneurobio.2011.02.002

Qi, Y., Morishima-Kawashima, M., Sato, T., Mitsumori, R., and Ihara, Y. (2003). Distinct mechanisms by mutant presenilin 1 and 2 leading to increased intracellular levels of amyloid beta-protein 42 in Chinese hamster ovary cells. Biochemistry 42, 1042-1052. doi: 10.1021/bi0267590

Roubaud-Baudron, C., Krolak-Salmon, P., Quadrio, I., Megraud, F., and Salles, N. (2012). Impact of chronic Helicobacter pylori infection on Alzheimer's disease: preliminary results. Neurobiol. Aging. 33, 1009-1011. doi: 10.1016/j.neurobiolaging.2011.10.021

Rui, Y., Tiwari, P., Xie, Z., and Zheng, J. Q. (2006). Acute impairment of mitochondrial trafficking by beta-amyloid peptides in hippocampal neurons. J. Neurosci. 26, 10480-10487. doi: 10.1523/JNEUROSCI.3231-06.2006 
Santarelli, L., Gabrielli, M., Cremonini, F., Santoliquido, A., Candelli, M., Nista, E. C., et al. (2004). Atrophic gastritis as a cause of hyperhomocysteinaemia. Aliment. Pharmacol. Ther. 19, 107-111. doi: 10.1046/j.1365-2036.2003. 01820.x

Sawayama, Y., Ariyama, I., Hamada, M., Otaguro, S., Machi, T., Taira, Y., et al. (2005). Association between chronic Helicobacter pylori infection and acute ischemic stroke: Fukuoka Harasanshin Atherosclerosis Trial (FHAT). Atherosclerosis 178, 303-309. doi: 10.1016/j.atherosclerosis.2004.08.025

Selkoe, D. J. (1998) The cell biology of beta-amyloid precursor protein and presenilin in Alzheimer's disease. Trends Cell Biol. 8, 447-453. doi: 10.1016/S09628924(98)01363-4

Seshadri, S., Beiser, A., Selhub, J., Jacques, P. F., Rosenberg, I. H., D’Agostino, R. B., et al. (2002). Plasma homocysteine as a risk factor for dementia and Alzheimer's disease. N. Engl. J. Med. 346, 476-483. doi: 10.1056/NEJMoa011613

Walsh, D. M., Klyubin, I., Fadeeva, J. V., Cullen, W. K., Anwyl, R., Wolfe, M. S., et al. (2002). Naturally secreted oligomers of amyloid beta protein potently inhibit hippocampal long-term potentiation in vivo. Nature 416, 535-539. doi: 10.1038/416535a

Wang, H. W., Pasternak, J. F., Kuo, H., Ristic, H., Lambert, M. P., Chromy, B., et al. (2002). Soluble oligomers of beta amyloid (1-42) inhibit long-term potentiation but not long-term depression in rat dentate gyrus. Brain Res. 924, 133-140. doi: 10.1016/S0006-8993(01)03058-X

Wang, X., Su, B., Siedlak, S. L., Moreira, P. I., Fujioka, H., Wang, Y., et al. (2008). Amyloid-beta overproduction causes abnormal mitochondrial dynamics via differential modulation of mitochondrial fission/fusion proteins. Proc. Natl. Acad. Sci. U.S.A. 105, 19318-19323. doi: 10.1073/pnas.0804871105

Wu, A., Derrico, C. A., Hatem, L., and Colvin, R. A. (1997). Alzheimer's amyloidbeta peptide inhibits sodium/calcium exchange measured in rat and human brain plasma membrane vesicles. Neuroscience 80, 675-684. doi: 10.1016/S03064522(97)00053-5

Xia, W., Zhang, J., Kholodenko, D., Citron, M., Podlisny, M. B., Teplow, D. B., et al. (1997). Enhanced production and oligomerization of the 42residue amyloid beta-protein by Chinese hamster ovary cells stably expressing mutant presenilins. J. Biol. Chem. 272, 7977-7982. doi: 10.1074/jbc.272. 12.7977

Zhang, Y., McLaughlin, R., Goodyer, C., and LeBlanc, A. (2002). Selective cytotoxicity of intracellular amyloid beta peptide1-42 through p53 and Bax in cultured primary human neurons. J. Cell Biol. 156, 519-529. doi: 10.1083/jcb.200110119

Conflict of Interest Statement: The authors declare that the research was conducted in the absence of any commercial or financial relationships that could be construed as a potential conflict of interest.

Received: 14 February 2014; accepted: 25 March 2014; published online: 11 April 2014. Citation: Wang X-L, Zeng J, Feng J, Tian Y-T, Liu Y-J, Qiu M, Yan X, Yang Y, Xiong Y, Zhang Z-H, Wang Q, Wang J-Z and Liu R (2014) Helicobacter pylori filtrate impairs spatial learning and memory in rats and increases $\beta$-amyloid by enhancing expression of presenilin-2. Front. Aging Neurosci. 6:66. doi: 10.3389/fnagi.2014.00066 This article was submitted to the journal Frontiers in Aging Neuroscience. Copyright (C) 2014 Wang, Zeng, Feng, Tian, Liu, Qiu, Yan, Yang, Xiong, Zhang, Wang, Wang and Liu. This is an open-access article distributed under the terms of the Creative Commons Attribution License (CC BY). The use, distribution or reproduction in other forums is permitted, provided the original author(s) or licensor are credited and that the original publication in this journal is cited, in accordance with accepted academic practice. No use, distribution or reproduction is permitted which does not comply with these terms. 